\title{
Innovation Report of Big Data on Marine Forecast on the North Line of Maritime Silk Road
}

\author{
Bo Lin ${ }^{1 *}$ \\ ${ }^{1}$ The National Marine Environmental Forecasting Center (NMEFC) of Ministry of Natural Resources of the People's Republic of \\ China, Beijing 100081
}

\begin{abstract}
Since the first Arctic expedition in China in 1999, the National Marine Environment Forecasting Center of China has undertaken safety guarantee tasks for the 9 batches of Arctic scientific expedition ships (teams) and 26 merchant ships to come and back the North Line of Maritime Silk Road in China. This paper summarized their successful experience and innovation achievements in big data application, emphatically introduced the innovation of big data infrastructure construction of Maritime Silk Road marine forecasting, that is, the establishment of independent marine observation system, the exploration of international cooperation mode of marine observation, as well as the participation in global regional observation plans. Besides, marine prediction business innovation, safety guarantee service innovation, and supercomputing technology innovation were included in the scientific and technological business innovation. Moreover, the innovation achievements include aspects of polar marine prediction big data, guarantee technology big data and supercomputing. Finally, the construction and development prospect on the North Line of Maritime Silk Road were briefly prospected.
\end{abstract}

\section{Introduction}

The 21st century Maritime Silk Road [1] North Line extended from the ancient Japan Route of Maritime Silk Road [2], and originated from Vladivostok, Russia, northward through the Sea of Okhotsk and the Bering Sea into the Arctic Ocean, then westward through the Arctic Northeast Passage[3], and through the Barents Sea or the Norwegian Sea to reach coastal ports of northern Europe or western European finally. It is a maritime passage connecting Northeast Asia with Northwest Europe. The accelerated ablation of Arctic ice and snow caused by global warming, the modernization and megaplasia of marine ships caused by the rapid development of science and technology as well as the rich natural resources of the Arctic, the international obligations of energy conservation and emission reduction undertaken by China, moreover, the responsibility of scientific cognition and peaceful development of the Arctic, all herald that the North Line of the Maritime Silk Road will certainly become a prosperous "maritime highway". The National Center for Marine Environment Forecasting of China (hereinafter referred to as the Forecasting Center) has realized the basic construction of marine prediction big data and scientific and technological business innovation of Maritime Silk Road by applying big data and other technologies in long-term business scientific research and foreign cooperation practice.

\section{Innovation In The Basic Construction of Marine Forecast Big Data on The North Line of Maritime Silk Road}

\subsection{Creation of an autonomous Arctic Ocean Observing System}

Satellite remote sensing information and Arctic expedition data were once the main data sources for Arctic marine forecasting at that time. Since 2012, by participating in the working processes of navigation observation, site operation, and aerial exploration, and using the ocean-seaice-meteorology-atmosphere boundary stereoscopic observation method combined with sounding balloons and sounding instruments, marine buoys and submarkers, and automatic meteorological stations, marine environment view (exploration, supervision) measurement data were collected and accumulated by the fifth and sixth Chinese Arctic Science and Technology Examination Teams. Based on this, marine environment forecasting applications and demonstration products [4] have been produced by Forecast Center on the spot to realize two business innovations: on-site observation and on-site forecasting of Arctic science and technology examinations. During the seventh and eighth Arctic scientific examination in 2016-2017, they navigated through the Arctic central passage for the first time on the basis of

\footnotetext{
*Corresponding author’s e-mail: linbo@nmefc.cn
} 
completing the ice survey tasks of Arctic science and technology examinations (Figure 1), and obtained many

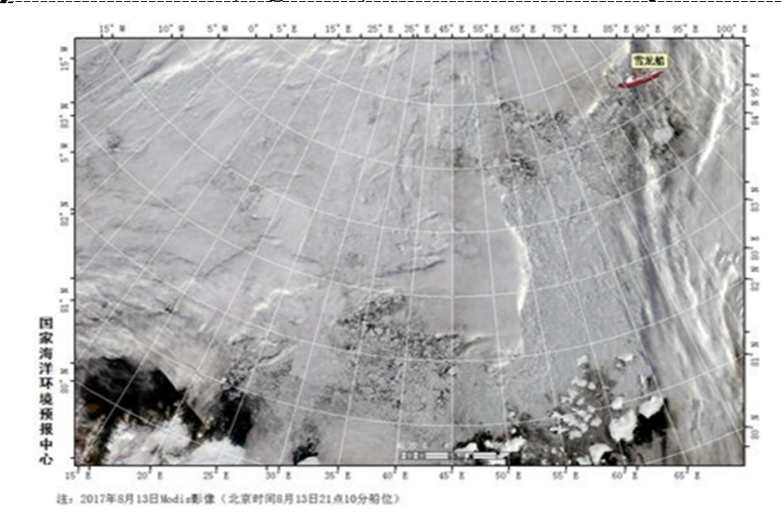

key data of marine space and atmospheric space in the main functional areas of Arctic oceans.

Figure 1. Navigation observation map of Arctic expedition underway (provided by Forecast Center)

\subsection{Exploring new models for international cooperation on Arctic observations}

In 2013, the "China-Finland Polar Atmosphere - Ice and Snow Sustainable Joint Monitoring and Numerical Simulation Study" was approved by the State Oceanic Administration for implementation [5], moreover, the Forecasting Center and the Finnish National Meteorological Administration took the lead in cooperating in the fields of polar sea ice and atmosphere field observation, data analysis and data assimilation technology, numerical simulation tests and prediction model research, and achieved a series of important results. In 2014, a "Memorandum of Understanding on Polar forecasting Cooperation" was signed with the Alfred Weigner Polar Institute in Germany, which agreed to strengthen cooperation in the field of marine and polar research, jointly optimize the use of polar observation networks, develop data assimilation technologies, and improve polar forecasting models [6]. In 2018, the Forecast Center participated in the national key R \& D plan "Intergovernmental Key Project for International Scientific and Technological Innovation Cooperation Research on Multi-element Space Observation and Information Service of Arctic Environment" [7], which cooperated by China and the European Union's 2020 plan "'Integrated Arctic Observation System (INTAROS)". It has entered the substantial research stage after joint efforts and preparation by both sides.

\subsection{Participation in regional plans for global ocean observations}

At the Scientific Steering Group of the Polar Prediction Program (PPP) of the World Meteorological Organization (WMO), the Forecasting Center cooperated with other member state institutions to carry out polar forecasting research based on observational data (Figure 2) and numerical models [8]; In terms of the Global Ocean Observing System (GOOS) Northeast Asian- Regional Ocean Observing System (NEAR-GOOS), the Center cooperated with Russia, Japan, South Korea and other member countries. It made every effort to promote countries around the world to share marine observation data and other cooperation achievements in the marine field free of charge [9]; In the participating of international Arctic Drifting Ice Station Program, relying on the German "Polarstern" ice breaker, by using the ocean and atmosphere within $50 \mathrm{~km}$ around the ice breaker as the main observation objects, combining with the application of "penetrating current", after a year of manual duty observation, a large number of marine data was collected from the East Siberian Sea to the Arctic Pole. It deepened the understanding of the coupling process between the "ocean-sea-atmosphere-ecology" systems in the central Arctic sea ice area, assisted in the investigation of the physical characteristics and elimination mechanism of Arctic sea fog as well as the exploration of the numerical simulation of Arctic sea fog [10]. 


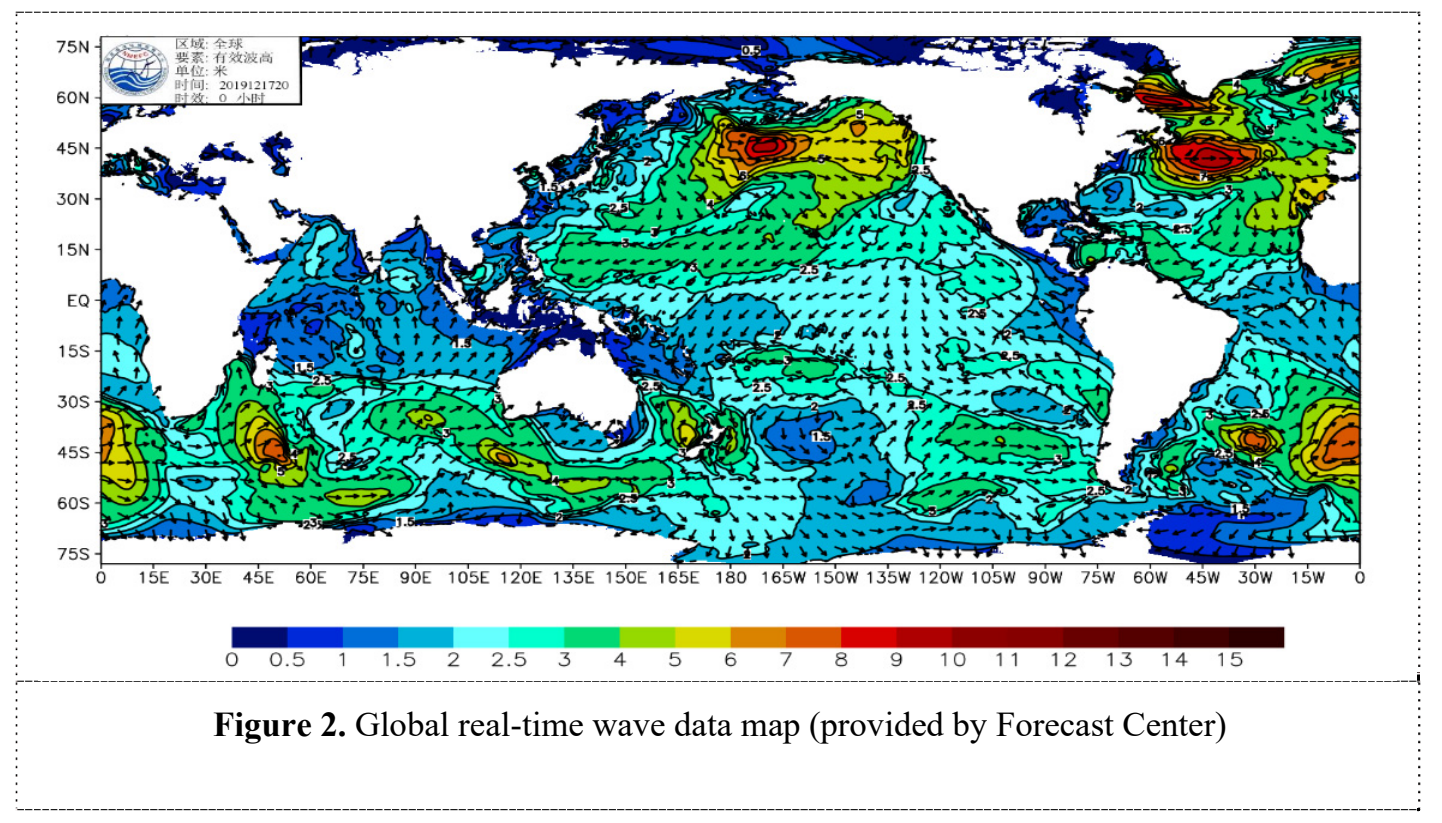

\section{Scientific And Technological Innovation of Marine Forecast Big Data Business on The North Line of Maritime Silk Road}

\subsection{Business Innovation of marine forecast}

In 2013, the Forecast Center was elected a member of the University of the Arctic (UArctic) [11], which has since opened the road to innovation in Arctic marine environment forecasting combining "industry, university and research". Arctic University organizations was a strong faculty lineup including experts from Canada, Denmark, Finland, Iceland, Norway, Sweden, Russia, the United States, China, the United Kingdom, Belgium, France, and Japan. It promoted the synchronous development of Arctic marine environment forecasting cooperative research and education. In 2015, the Forecasting Center specially invited senior experts in the research and development of polar sea ice numerical simulation and forecasting systems of the National Center for Environmental Forecasting to come to Beijing for lectures to open a series of lectures on polar climate models, sea ice models, data assimilation, ensemble forecasting, forecasting and inspection. It cooperated to carry out medium- and long-term numerical forecasting tests of Arctic sea ice using the Climate Forecasting System (CFSv2). Moreover, it successfully applied them to the Arctic science expedition and Merchant Shipping First Flight Forecasting Support Service [12]. Besides, it jointly organized six Arctic Forecasting Seminars with foreign scientific research institutions to jointly discuss and develop Arctic marine and atmospheric forecasting systems.

\subsection{Innovation of safety guarantee services}

In 2018, the "China Ocean Forecasting Network" developed by the Forecast Center went online [13]. At present, China's only national professional website for marine forecasting marks that China's global futureoriented marine environment forecasting and guarantee service has comprehensively entered the new era of "Internet + " and "mobile Internet $+"$. As a professional platform for marine forecasting and early warning information in China, this website authoritatively publishes the early warning (forecasting) information of marine disasters such as sea waves, sea ice (Figure 3), storm surge, tsunami, red tide, green tide, sea temperature and sea current, and integrates professional marine forecasting and guarantee services, information and public scientific knowledge. Through mobile applications and WAP services, it realizes expert answering and answering interactions, and its service surface seamlessly covers the global oceans and poles. Subsequently, the marine environment forecasting and guarantee system of the Maritime Silk Road entered the operational operation through the "Special Passage of the Maritime Silk Road" of the China Ocean Forecasting Network, which released the marine environment forecasting information products along the Maritime Silk Road in Chinese and English [14]. 


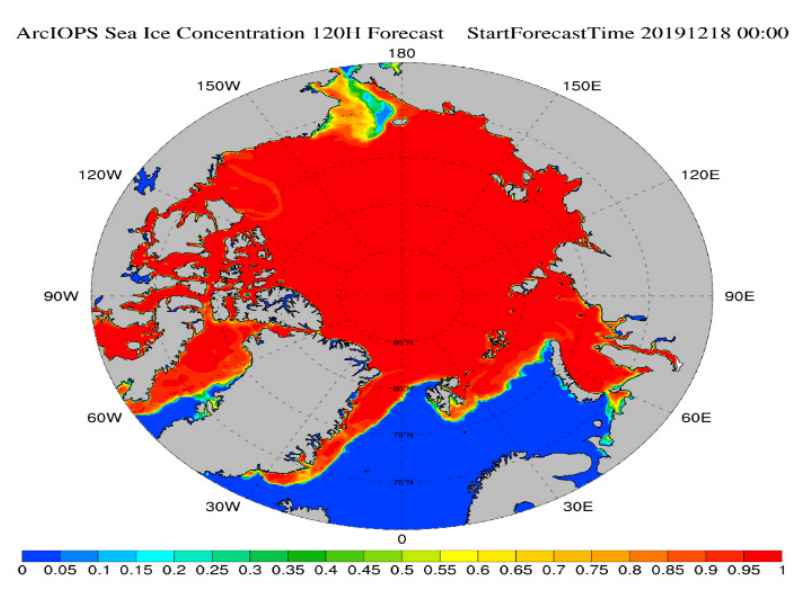

Figure 3. Big data of Arctic sea ice prediction (provided by the Forecasting Center)

\subsection{Technology innovation in supercomputing}

In the field of marine environment forecasting, marine real-time observation data, marine forecasting information and marine environment guarantee service data all belong to the category of big data. Global, especially polar marine environment forecasting, is increasingly dependent on high-performance computing, there is no modern marine forecasting without high-performance computing. Highperformance computing technology and research has been promoted from the past auxiliary role to the status of marine forecasting science and technology. Driven by scientific and technological innovation, the Forecasting Center has formed a computing resource pool composed of marine real-time data center, marine supercomputing center, marine forecasting numerical model software set, global marine monitoring and forecasting data lake, global marine environment forecasting business network, marine cloud computing and big data visualization intelligent platform, Shenwei $3000+$ high-performance computing system + IBM blade cluster, etc., which is enough to ensure the sustainability of marine prediction innovation on the Marine North Silk Road. In 2017, the Forecast Center joined the National Supercomputing Innovation Alliance and served as a member of the Technology and Standards Group of the Alliance.

\section{Innovative Achievements in The Application of Big Data for Marine Prediction on the North Line of Maritime Silk Road}

\subsection{Innovative achievements in global ocean forecasting}

The global operational oceanographic forecasting system is the first independent numerical forecasting system of oceanic and polar (Figure 4) and offshore nested in China mainly developed by the Forecasting Center, which realizes the full coverage of integrated marine forecasting business from 100-kilometer to kilometer spatial resolution worldwide. The successful application of this system has reversed the situation of long-term use of foreign marine forecasting products in China and become a few countries that can independently carry out global operational marine forecasting after the United States and the European Union. In 2017, through the application evaluation, the expert group evaluated that the achievements had reached the international advanced level as a whole, of which the physical parameterization scheme, assimilation of independent dynamic satellite data, application of environmental forecasting technology and other aspects had been in the international leading position [15]. It was rated as the first prize of "Top Ten Marine Science and Technology Progress in China in 2013" and won the First Prize of China Marine Science and Technology Award in 2015, moreover, it was selected as the "National Twelfth Five-Year Scientific and Technological Innovation Achievement Exhibition" with the theme of "Innovation-Driven Development - Science and Technology Leading the Future" in 2016. 


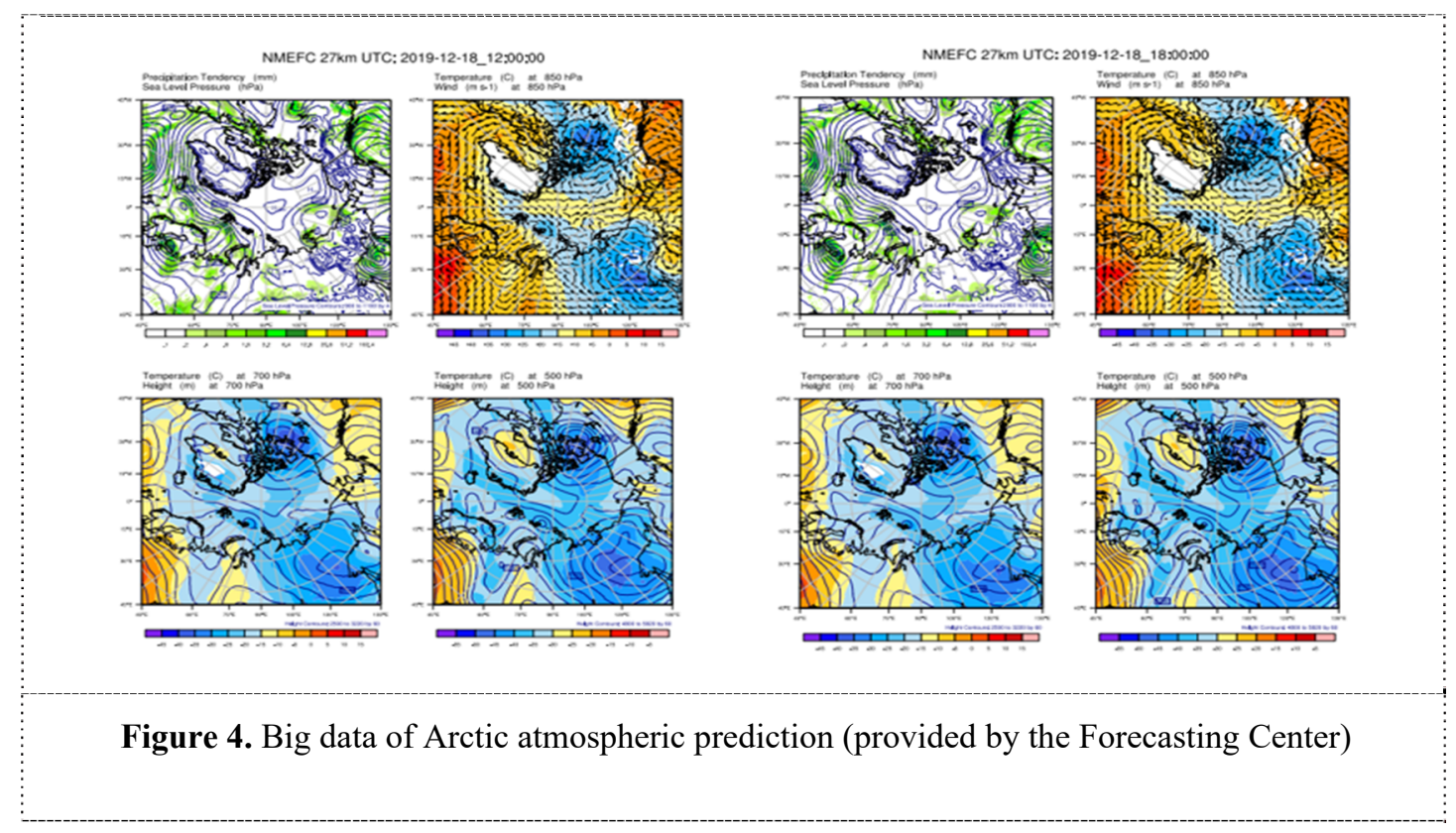

\subsection{Innovation achievements of Polar safeguard technology}

After entering the 21 st century, actively responding to climate change, the Forecast Center timely intervened in the research on marine environment forecasting and guarantee services for commercial and trade navigation of Arctic passages, as well as completed a total of 9 batches of marine environment forecasting and guarantee tasks for Arctic scientific research in China. Moreover, it successively provided forecasting and guarantee for the North Line of Maritime Silk Road round-trip navigation of 26 voyages of 17 commercial vessels including China Ocean Ocean Shipping Group (Figure 5). In the 2016 "Yongsheng Wheel +" project, 6 navigation vessels in
North Line of Maritime Silk Road saved the voyage of 32137 knots total, 108 days of voyage, and 4077 tons of dynamic fuel, greatly reduced the operating costs of commercial vessels and carbon emissions and environmental pollution [16]. The normalization of commercial shipping on the North Line of Maritime Silk Road extends the traditional "Maritime Silk Road" Oriental Airline north and west, directly to Europe through the Arctic Ocean. The important research project "Research and Application of Marine Meteorological Support Technology for Polar Navigation" participated by the Forecast Center and based on North Line of Maritime Silk Road won the first prize of China Navigation Science and Technology Award in 2008, and "Research and Application of Key Technologies for Chinese Merchant Ships to Open up Polar Airlines" won the special prize of China Navigation Science and Technology Award in 2018.

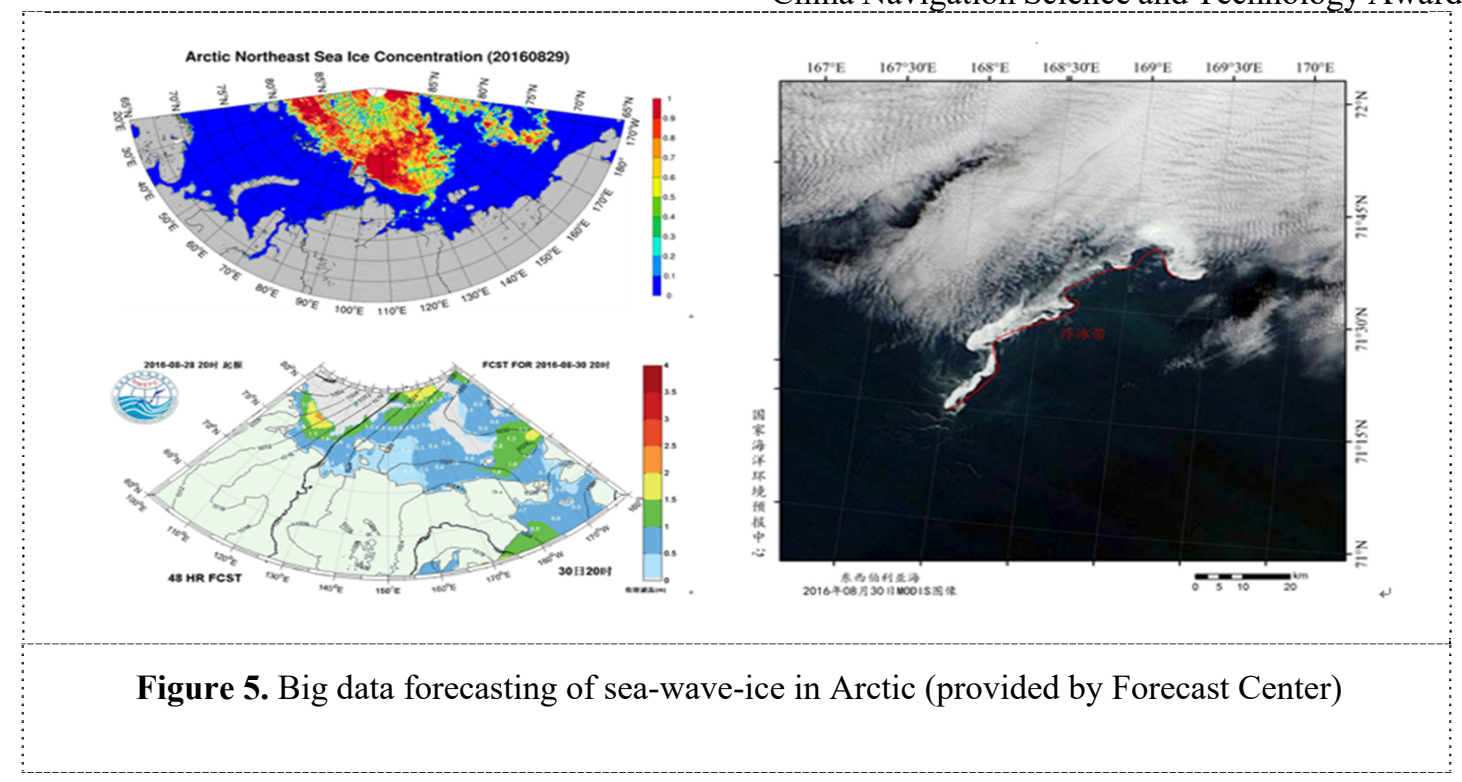




\subsection{Innovative outcomes of marine supercomputing}

As a member of the Global Operational Ocean Forecasting Organization (GOV), the Forecast Center has made new progress in the fields of data assimilation, numerical modeling, and business process optimization of the Chinese Global Operational Oceanography Forecasting System (CGOFS), especially in the exploration and research of polar science examination and "Maritime Silk Road" commercial shipping, such as the research and application of the "Current-Wave-Ice-Atmosphere Coupled Forecast System", marine monitoring and forecasting cloud computing and big data technology, and the construction of the intelligent platform for global ocean forecasting visualization. In the last 5 years, the research results and theme papers such as "Application Research of NEMO in Global Marine Environment Model forecasting", "Computational Performance Optimization of Global Marine Environment Forecasting Model Based on NEMO in Overcalculation Cluster", "Coupling Parallel of Global Atmosphere-Ocean Wave Numerical Calculation Model" (Figure 6), and "Parallel Optimization of Typhoon Coupled Numerical Calculation Model" have won the Bronze Award and Excellent Paper Award of the Annual Finals of the "National Parallel Application Challenge (PAC)" for 4 consecutive years.

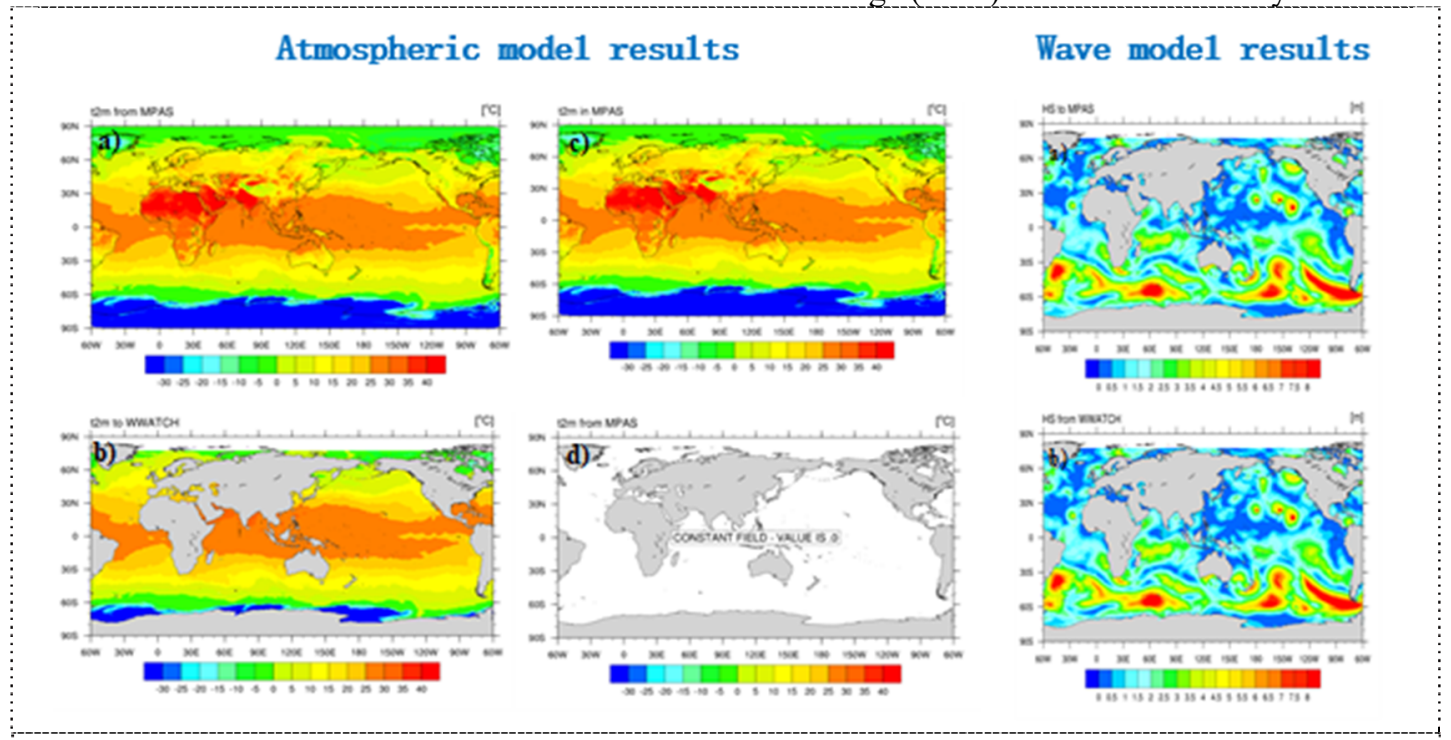

Figure 6. Big data of atmosphere-wave optimization model (provided by Forecast Center)

\section{Expectation}

The North Line of the Maritime Silk Road, also known as the "Silk Road on the Ice [17]", is a maritime transportation artery that provide promotion on the economic development of Northeast Asia, the deepening of strategic cooperation between China and Russia as well as the progress of Arctic scientific investigation. The Forecasting Center will, in combination with the Arctic scientific investigation and marine prediction guarantee service business, besides, with the further promotion of multiple levels such as marine observation, marine forecasting, scientific research, technological innovation, and international cooperation, strive to build a big data project for the sustainable development of marine forecasting on the North Line of the Maritime Silk Road. It will bear the important task of Arctic scientific investigation and marine prediction guarantee service for commercial shipping on the Maritime Silk Road. The Forecasting Center will achieve new and greater contributions to the development of the Arctic cause and the world economy, and more importantly, the prosperity of the community with shared future.

\section{References}

1. Author. Editorial group of this book: Xi Jinping Talks about Governance (Volume I). [ M]. Beijing, Foreign Language Press, January 2018 (2nd Edition), pp. 292-295

2. Yao Q.H. Hu X.P. (2018) "The Silk Road at the 21st Century" and the New Mechanism for Regional Cooperation. Shanghai Academy of Social Sciences Press, Shanghai.

3. Li Z.F. (2016) A Strategic Study of the Arctic Route of the Silk Road, Dalian Maritime University Press, Dalian.

4. National Marine Environmental Forecasting Center, 2014. News_2014.07.15. http://www.nmefc.cn/

5. National Marine Environmental Forecasting Center, 2014. News_2014.10.23. http://www.nmefc.cn/

6. National Marine Environmental Forecasting Center, 2014. News_2014.12.08. http://www.nmefc.cn/

7. National Marine Environmental Forecasting Center, 2018. News_2018.10.26. http://www.nmefc.cn/

8. National Marine Environmental Forecasting Center, 2016. News_2016.05.30. http://www.nmefc.cn/ 
9. National Marine Environmental Forecasting Center, 2017. News_2017.12.05. http://www.nmefc.cn/

10. National Marine Environmental Forecasting Center, 2018. News_2018.08.15. http://www.nmefc.cn/

11. National Marine Environmental Forecasting Center, 2013. News_2013.06.14. http://www.nmefc.cn/

12. National Marine Environmental Forecasting Center, 2015. News_2015.07.10. http://www.nmefc.cn/

13. National Marine Environmental Forecasting Center, 2018. News_2018.12.14. http://www.nmefc.cn/

14. National Marine Environmental Forecasting Center, 2018. News_2018.12.26. http://www.nmefc.cn/

15. National Marine Environmental Forecasting Center, 2017. News_2017.12.21. http://www.nmefc.cn/

16. National Marine Environmental Forecasting Center, 2016. News_2016.10.17. http://www.nmefc.cn/

17. Journal. Liu Guobin: Research on Silk Road Construction on Ice. [ J]. Changchun, Northeast Asia Economic Research, December 2019, Issue 6 Total No. 16, Pages 5-15 